\title{
Identification and characterization of two distinct PPP1R2 isoforms in human spermatozoa
}

\author{
Luis Korrodi-Gregório ${ }^{1}$, Mónica Ferreira ${ }^{1}$, Ana Paula Vintém¹, Wenjuan $\mathrm{Wu}^{1}$, Thorsten Muller², Katrin Marcus², \\ Srinivasan Vijayaraghavan ${ }^{3}$, David L Brautigan ${ }^{4}$, Odete A B da Cruz e Silva ${ }^{5}$, Margarida Fardilha, ${ }^{6,7^{*}}$ \\ and Edgar F da Cruz e Silva ${ }^{1 \wedge}$
}

\begin{abstract}
Background: Protein Ser/Thr Phosphatase PPP1CC2 is an alternatively spliced isoform of PPP1C that is highly enriched in testis and selectively expressed in sperm. Addition of the phosphatase inhibitor toxins okadaic acid or calyculin A to caput and caudal sperm triggers and stimulates motility, respectively. Thus, the endogenous mechanisms of phosphatase inhibition are fundamental for controlling sperm function and should be characterized. Preliminary results have shown a protein phosphatase inhibitor activity resembling PPP1R2 in bovine and primate spermatozoa.

Results: Here we show conclusively, for the first time, that PPP1R2 is present in sperm. In addition, we have also identified a novel protein, PPP1R2P3. The latter was previously thought to be an intron-less pseudogene. We show that the protein corresponding to the pseudogene is expressed. It has PPP1 inhibitory potency similar to PPP1R2. The potential phosphosites in PPP1R2 are substituted by non-phosphorylable residues, T73P and S87R, in PPP1R2P3. We also confirm that PPP1R2/PPP1R2P3 are phosphorylated at Ser121 and Ser122, and report a novel phosphorylation site, Ser127. Subfractionation of sperm structures show that PPP1CC2, PPP1R2/PPP1R2P3 are located in the head and tail structures.

Conclusions: The conclusive identification and localization of sperm PPP1R2 and PPP1R2P3 lays the basis for future studies on their roles in acrosome reaction, sperm motility and hyperactivation. An intriguing possibility is that a switch in PPP1CC2 inhibitory subunits could be the trigger for sperm motility in the epididymis and/or sperm hyperactivation in the female reproductive tract.
\end{abstract}

Keywords: PP1, Phosphorylation, PP1 interacting protein, PPP1R2, PPP1R2P3, Pseudogene

\section{Background}

Spermatozoa are specialized cells that are highly compartmentalized, transcriptionally inactive and unable to synthesize new proteins. Protein phosphorylation is a post-translational mechanism that plays a crucial role in sperm physiology, controlling motility, capacitation, hyperactivated motility and the acrosome reaction [1,2]. Low sperm motility is one of the main causes of male

\footnotetext{
*Correspondence: mfardilha@ua.pt

Deceased

'Laboratory of Signal Transduction, Centre for Cell Biology, Biology Department; Health Sciences Department, University of Aveiro, 3810-193

Aveiro, Portugal

${ }^{7}$ Centro de Biologia Celular, Universidade de Aveiro, 3810-193 Aveiro, Portugal

Full list of author information is available at the end of the article
}

infertility [2]. The biochemical mechanisms essential for the development of motility are still far from understood, however, serine/threonine protein phosphatase 1 (PPP1) and glycogen synthase kinase 3 (GSK3), have been recognized as components of the regulatory mechanism [3-5]. Three separate genes $(\alpha / A, \beta / \delta / B$ and $\gamma / C)$ encode the catalytic subunit of PPP1 (PPP1C). PPP1CC undergoes alternative splicing, giving rise to a ubiquitous isoform PPP1CC1 and a testis-enriched and sperm specific-isoform, PPP1CC2 [3,5]. PPP1CC2 is the only PPP1 isoform highly enriched in bovine, rhesus monkey and human sperm $[3,5]$. The phosphatase is distributed along the entire flagellum, including the mid-piece, consistent with a role in sperm motility, and also in the posterior and equatorial regions of the head, suggesting a

\section{Biomed Central}

(c) 2013 Korrodi-Gregório et al.; licensee BioMed Central Ltd. This is an Open Access article distributed under the terms of the Creative Commons Attribution License (http://creativecommons.org/licenses/by/2.0), which permits unrestricted use, distribution, and reproduction in any medium, provided the original work is properly cited. 
role in the acrosome reaction [2,6,7]. The observation that PPP1C had a two-fold higher activity in immotile bovine caput epididymal sperm compared to mature motile caudal sperm is consistent with it being directly involved in sperm motility [3,5]. Moreover, inhibition of PPP1CC2 activity by the toxins okadaic acid or calyculin A induced and stimulated motility in caput and caudal sperm, respectively [3,5]. Homozygous knockout mice for Ppp1cc gene (a deletion of both isoforms) lead to sterility of male but not female mice. The sterility resulted from a combination of gross structural defects in spermatids that cause apoptosis and lack of spermiation $[8,9]$. The evolutionary conservation and the importance of Ser/Thr phosphatases in regulating flagellar motility, is highlighted by the involvement of a PPP1 homolog in the regulation of rooster sperm motility [10] and by the involvement of a Ser/Thr phosphatase in the regulation of microtubule sliding velocity in Paramecium and Chlamydomonas [11,12].

Regulation of PPP1 catalytic activity is mediated via binding to specific regulatory subunits, the PPP1 interacting proteins [13-15]. The extensive diversity of such interacting proteins and their tissue specificity makes them potential pharmacological targets [14]. To date, studies have shown that sperm do not appear to contain PPP1R1 (inhibitor-1, I1), whose activity is controlled by protein kinase A phosphorylation $[3,5,16]$. However, a PPP1R2-like activity seems to be present in sperm due to its sensitivity to GSK3 phosphorylation [3,5]. PPP1 and PPP1R2 are known to form a stable, catalytically inactive heterodimer, also known as MgATP-dependent phosphatase [17]. PPP1R2 can also bind and regulate PPP1C already complexed to other regulatory subunits [17]. Phosphorylation of PPP1R2 at Thr73 by GSK3 releases the inhibition and the phosphatase becomes active [18]. Immotile caput sperm contained sixfold higher GSK3 activity than motile caudal sperm [3,5]. The presence and activity of GSK3 in sperm has been further characterized, emphasizing its role in sperm motility regulation $[19,20]$.

Recent experiments have demonstrated that sperm also contains the homologue of the yeast PPP1 binding protein, PPP1R7 (Sds22) and that the complex with PPP1CC2 is catalytically inactive [6]. Finally, a potent heat-stable inhibitor was identified as the orthologue of the mouse $t$ complex testis-expressed gene Tctex5, also known as PPP1R11 (inhibitor 3, I3) [21]. The heat stability of these inhibitors is important for facilitating the purification, although no other function was found so far for this property. It was also shown that both inhibitors, PPP1R7 and PPP1R11, form a catalytically inactive multi-complex with PPP1CC2 in sperm [22].

Despite these findings whether sperm contain PPP1R2 remains undetermined. The purpose of this study was to determine if PPP1R2 was present in spermatozoa. We show here, for the first time, the presence and localization of PPP1R2 in human spermatozoa. Furthermore, we demonstrate the presence of PPP1R2P3, a new isoform of PPP1R2. The gene corresponding to PPP1R2P3 was previously designated as an intron-less pseudogene [23]. Our studies raise the intriguing possibility that the interplay between PPP1CC2/PPP1R2 and PPP1CC2/PPP1R2P3 could operate to regulate human sperm function.

\section{Results and discussion}

Identification of PPP1R2P3 - a novel PPP1R2 isoform in testis

The catalytic subunit isoforms PPP1CC1 and PPP1CC2 were used as baits to screen a human testis cDNA library by yeast two-hybrid $[2,15]$. From the PPP1CC1 screening, 120 positive clones were recovered, one of which encoded the complete sequence of a novel isoform of the regulatory protein known as PPP1R2 or inhibitor 2 (I2). This novel clone is located on chromosome 5, aligns to the sequence ID:NR002168 and is classified as PPP1R2 pseudogene 3 (PPP1R2P3). While PPP1R2 is present on chromosome 3 and is encoded by 5 exons, PPP1R2P3 is an intronless gene and therefore was designated as a probable pseudogene by both NCBI and Ensembl databases. This clone has been deposited in the GenBank database under the ID:JF438008.1 [2,15]. The PPP1R2P3 mRNA is also present in human testis cDNA library repository of the Mammalian Gene Collection (MGC) program (nucleotide ID: BC066922; protein ID: Q6NXS1) [24]. By searching Unigene (NCBI) for PPP1R2P3 specific expressed sequence tags (ESTs) 15 ESTs were obtained, of which 14 are from testis. These ESTs are specific for this pseudogene and cover close to $65 \%$ of the PPP1R2P3 nucleotide sequence including the CDS. Taken together, our results, the ESTs, and the MGC results [24], support the proposal that PPP1R2P3 is not a pseudogene and is indeed expressed in testis. Furthermore, by blast search we only found orthologs of this pseudogene in primate's assembly genomes.

PPP1R2P3 has only 16 nucleotide substitutions (92.2\%, identity) relative to PPP1R2, which correspond to 9 amino acid changes (95\%, identity) in the translated sequence. Comparing the PPP1R2P3 protein sequence with that of the PPP1R2 using ClustalW2, we found that all the PPP1C binding regions are maintained (Figure 1). However, there are important differences between PPP1R2 and PPP1R2P3, in that the phosphorylation sites of the latter, for GSK3 (Thr73) and CK2 kinase (Ser87), appear as Pro and Arg, respectively (Figure 1).

\section{PPP1R2P3 interacts and inhibits PPP1C}

To validate the yeast two-hybrid result we re-confirmed the PPP1R2P3 interaction with different PPP1C isoforms. The sequential yeast co-transformation, showed the interaction of PPP1R2P3 with PPP1CA, PPP1CC1 and PPP1CC2 and 


\begin{tabular}{|c|c|c|}
\hline & RVxF degenerate motif & \\
\hline PPP1R2 & MAASTASHRPIKGILKNKTSTTSSMVASAEQPRGNVDEELSKKSQKWPEMNILATYHPAD & 60 \\
\hline PPP1R2P3 & $\begin{array}{l}\text { MAASTASHRPIKGILKNKTSTTSSMVASAEQPRRSVDEELSKRSQKWDEINILATYHPAD } \\
* * * * * * * * * * * * * * * * * * * * * * * * * * * * * * * * *\end{array}$ & 60 \\
\hline PPP1R2 & $\begin{array}{c}\downarrow \text { GSK3 } \\
\text { KDYGLMKIDEPSTPYHSMMGDDEDACSDTEATEAMAPDILARKLAAAEGLEPKYRIQEQE }\end{array}$ & 120 \\
\hline PPP1R2P3 & 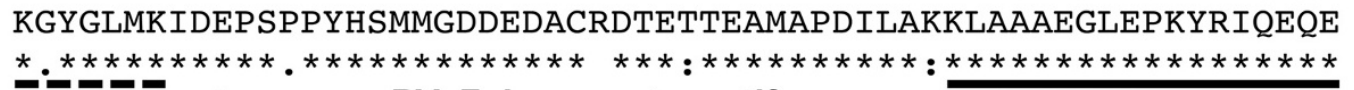 & 120 \\
\hline PPP & $\begin{array}{lccc}\downarrow \downarrow \mathbf{C K 2} & \downarrow \text { RVxF degenerate motif } & \text { Acidic stretch } \\
\text { SSGEEDSDLSPEEREKKROFEMKR KLHYNEGLNIKLAROLISKDLHDDDEDEEMLETADG }\end{array}$ & 180 \\
\hline PPP1R2P 3 & 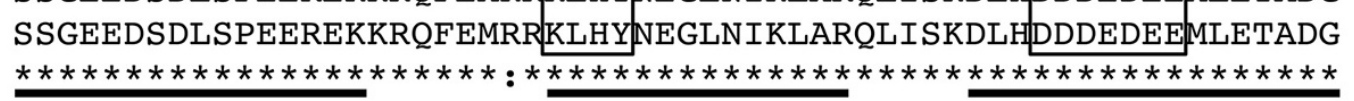 & 180 \\
\hline $\begin{array}{l}\text { PPP1R2 } \\
\text { PPP1R2P3 }\end{array}$ & $\begin{array}{ll}\text { ESMNTEESNQGSTPSDQQQNKLRSS } & 205 \\
\text { ESMNTEESNQGSTPSDQQQNKLRSS } & 205 \\
\star * * * * * * * * * * * * * * * * * * * * * * * * & \end{array}$ & \\
\hline \multicolumn{3}{|c|}{$\begin{array}{l}\text { Figure } 1 \text { ClustalW2 alignment of PPP1R2 and PPP1R2P3. Protein sequences for PPP1R2 and PPP1R2P3 were obtained from Uniprot database. } \\
\text { Sequences were submitted to a ClustalW2 alignment. Relevant motifs/regions for PPP1R2/PPP1R2P3 binding to PPP1C are shown in open boxes. } \\
\text { Important phosphorylation sites are indicated with black arrows above the residues and with the respective known kinase. * represent high } \\
\text { conservation, : and. represent low conservation in which the substituted residue has respectively more and less similar properties. Black } \\
\text { horizontal bars below the protein sequences show the coverage of the peptides obtained by mass spectrometry. Black horizontal dash bar } \\
\text { indicates the peptide that allowed for the distinction between PPP1R2P3 from PPP1R2. Black horizontal square dot bar indicates the peptide that } \\
\text { allowed distinguishing PPP1R2. }\end{array}$} \\
\hline
\end{tabular}

with the unique C-terminal of PPP1CC2 (PPP1CC2end) (Figure 2A). The apparent relative lack of specificity toward the PPP1C isoforms may arise given that in yeast Cotransformation the interaction is forced and happens inside the nucleus. In vivo, the PPP1C isoforms have different tissue/cellular and subcellular localizations that would influence the PPP1R2P3 interaction. In order to compare the binding of PPP1R2 and PPP1R2P3 to PPP1CC isoforms, and demonstrate the interaction as direct, a blot overlay was performed (Figure 2B). A blot containing the same amount of commercial PPP1R2 or His-PPP1R2P3 was incubated with PPP1CC1 or PPP1CC2 and the interaction detected using the $\mathrm{CBC} 3 \mathrm{C}$ and the $\mathrm{CBC} 502$ antibodies, respectively (Figure 2B). The binding of PPP1R2P3 to both PPP1CC isoforms was confirmed and the binding was similar to that of PPP1R2.

Since PPP1R2 is a potent heat-stable inhibitor of PPP1 in the nanomolar range [25], we decided to determine whether PPP1R2P3 is heat-stable, if it exhibited PPP1 inhibitory activity, and if so, what was the potency compared to that of PPP1R2. We determined the IC50 values of recombinant His-PPP1R2P3 for the PPP1CC isoforms using the standard phosphorylase phosphatase assay [26]. Results showed that PPP1R2P3 is a potent heat-stable inhibitor of PPP1C with a doseresponse curve similar to the commercial PPP1R2 (Figure 3A) and IC50 values in the subnanomolar range (Figure 3B, PPP1CC1, $0.73 \pm 0.10 \mathrm{nM}$ and $\mathrm{PPP} 1 \mathrm{CC} 2,0.09 \pm 0.08 \mathrm{nM})$.

\section{GSK3 does not phosphorylate PPP1R2P3 in vitro}

Phosphorylation of PPP1R2 at Thr73 (in rabbit) by GSK3, relieves the inhibition of PPP1C and the complex PPP1C/PPP1R2 becomes active [18]. Also, phosphorylation by CK2 at the serines 87, 121 and 122 enhances Thr73 phosphorylation $[27,28]$. The absence of the GSK3 phosphorylation site, Thr73, and of the CK2 phosphorylation site, Ser87, in PPP1R2P3 led us to test the phosphorylation of PPP1R2P3 by these kinases. PPP1R2 and PPP1R2P3 were incubated in parallel reactions with GSK3, or CK2, or both, in the presence of 32P-ATP. PPP1R2 is known to be a poor substrate for GSK3 alone in vitro, but synergistic phosphorylation can be observed if phosphorylated by CK2 plus GSK3 [28]. In our hands this occurred with recombinant PPP1R2 (Figure 4, first panel). However, under the same conditions, no PPP1R2P3 phosphorylation by GSK3 was detected and the phosphorylation in the presence of both kinases was the same as with CK2 alone (Figure 4, second panel). The results indicate that there is no site for GSK3 phosphorylation in PPP1R2P3 and that CK2 is still able to phosphorylate but in other residue rather than Ser87.

\section{PPP1R2 and PPP1R2P3 are present in human ejaculated} sperm

Based on previous biochemical studies it was suggested that sperm PPP1CC2 is regulated by a PPP1R2-like activity $[3,5]$. However, there was no definitive evidence for the presence of PPP1R2 in spermatozoa. Efforts to 
A

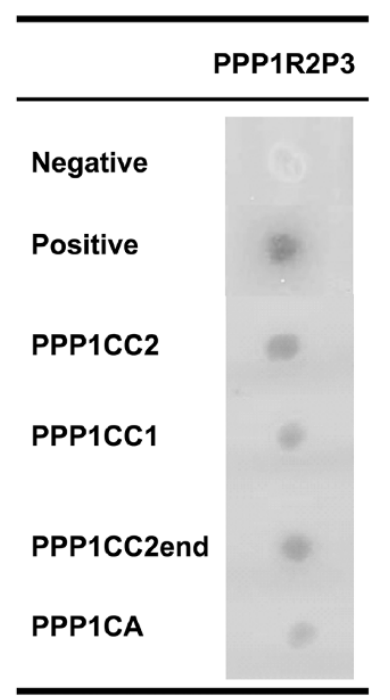

B

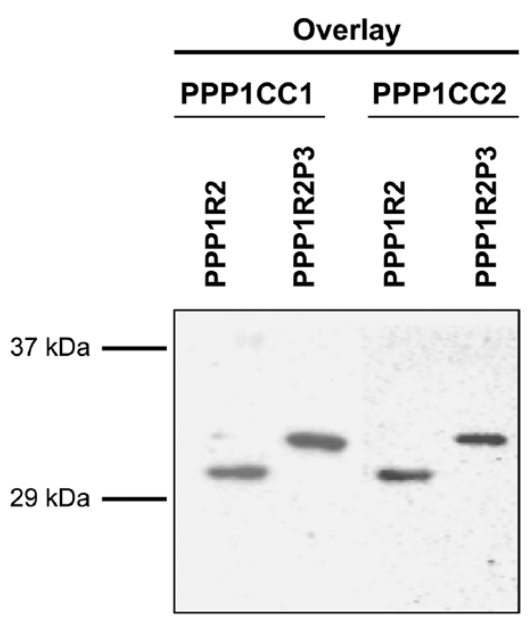

Figure 2 Interaction of PPP1R2P3 with different PPP1 isoforms. (A), Sequential transformation of yeast AH109 with bait plasmid (pAS2PPP1CA, pAS2-PPP1CC1, pAS2-PPP1CC2, or pAS2-PPP1CC2end) and the prey plasmid PACT2-PPP1R2P3. pAS2-PPP1CC2end is the unique C-terminal tail of PPP1CC2 produced by alternative splicing of the PPP1CC gene. For negative and positive controls pAS2-1/pACT-2 and pVA3-1/pTD1-1 vectors were used, respectively (B), Overlay assay of PPP1R2 and PPP1R2P3. Commercial PPP1R2 and His-PPP1R2P3 were separated by SDS-PAGE, transferred to nitrocellulose and overlaid with recombinant PPP1CC1 or PPP1CC2, as indicated. Western blotting was performed with the respective specific antibodies.

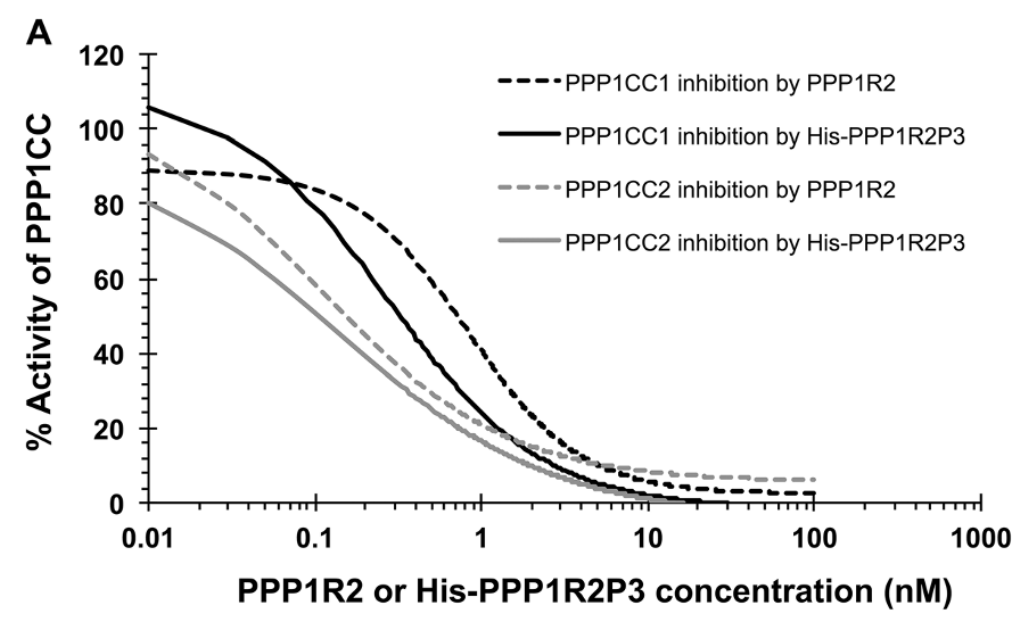

B

\begin{tabular}{|c|c|c|}
\cline { 2 - 3 } \multicolumn{1}{c|}{} & \multicolumn{2}{c|}{ IC50 (nM) ${ }^{\mathrm{a}}$} \\
\hline Isoforms & PPP1R2 & His-PPP1R2P3 \\
\hline His-PPP1CC1 & $0.27 \pm 0.09$ & $0.73 \pm 0.10$ \\
\hline His-PPP1CC2 & $0.14 \pm 0.04$ & $0.09 \pm 0.08$ \\
\hline
\end{tabular}

Figure 3 PPP1R2 and PPP1R2P3 inhibit PPP1CC. (A), Graphical representation of PPP1CC1 and PPP1CC2 inhibition curves by commercial PPP1R2 and His-PPP1R2P3, using phosphorylase a as substrate. (B), Table showing the comparison of PPP1CC isoforms IC50s by PPP1R2 and PPP1R2P3 using the phosphorylase phosphatase assay. ${ }^{\mathbf{a}}$ The values are expressed as the mean \pm S.E.M. of at least three independent experiments. 


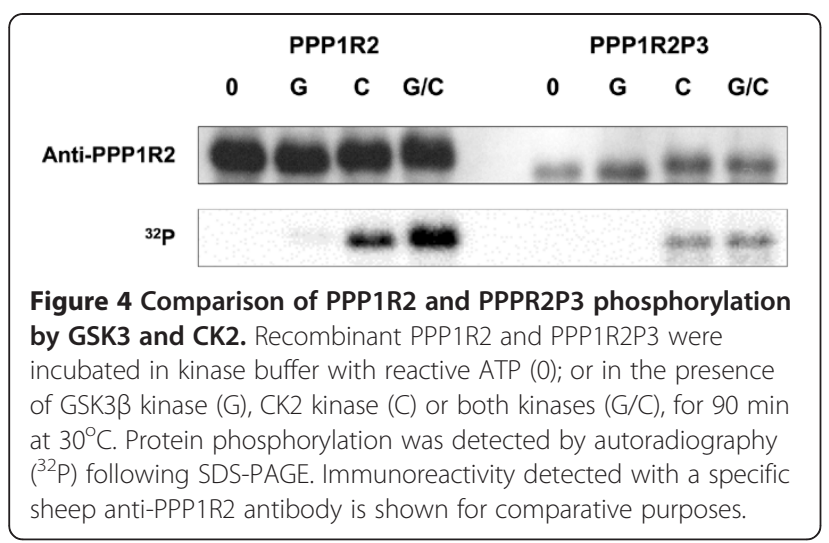

identify PPP1R2 at the protein level in testis and sperm have proven to be difficult because of the low amount of protein in soluble extracts and the quality of the available antibodies. PPP1R2 is an intrinsically unstructured protein (IUP) with a high proportion of charged and hydrophilic residues versus few hydrophobic residues [29]. Proteins such as PPP1R2 (predicted, $23 \mathrm{kDa}$ ), will migrate in SDS-PAGE at a position corresponding to a higher molecular mass than predicted by the primary sequence (i.e. $32 \mathrm{kDa}$ ) [30,31]. PPP1R2P3 has the same predicted molecular mass of PPP1R2 and in SDS-PAGE migrated at the same position of $32 \mathrm{kDa}$ (Figure 2B). To deal with the low abundance and taking advantage of the fact that PPP1R2 is heat-stable, protein precipitation was used to concentrate the samples from heat-treated extracts [32]. So far only one report showed successful identification of PPP1R2 in heat-stable extracts of bull testis and mouse testis and sperm using a PPP1R2 antibody (rabbit anti-PPP1R2, see Methods) raised in rabbit against an affinity-purified peptide $\left({ }^{135}\right.$ REKKRQFEMKRKLH ${ }^{148}$ from the mouse sequence) [33].

We used a sheep polyclonal anti-PPP1R2 antibody, raised against purified rabbit PPP1R2 as immunogen to detect PPP1R2/PPP1R2P3 as a band around the expected size (32 kDa) in testis and sperm extracts (Figure 5A) [34]. To demonstrate the presence of PPP1CC in the same extracts, an antibody against the C-terminus of PPP1CC was used (CBC3C). We detected two bands in testis that correspond to PPP1CC1 and PPP1CC2, while only one band, PPP1CC2, was detected in sperm, as expected [3,5]. Moreover, since PPP1R2 and PPP1R2P3 are heat-stable inhibitors, we heated RIPA extracts by boiling. Western blotting revealed a band corresponding to PPP1R2/PPP1R2P3 at the expected size of $32 \mathrm{kDa}$ (Figure 5B, second lane). To unequivocally demonstrate the existence of PPP1R2 and the new PPP1R2P3 isoform in human sperm we performed an immunoprecipitation of PPP1R2/PPP1R2P3 from five independent human ejaculated sperm samples (using anti-PPP1R2 antibodies (four using the sheep anti-PPP1R2 and one using the rabbit anti-PPP1R2) followed by mass spectrometry analysis. Immunoprecipitation was performed using heat-stable extracts of human ejaculates. We immunoprecipitated sufficient amounts of PPP1R2/ PPP1R2P3 for detection of their peptides by mass spectrometry (Table 1). Using the Orbitrap Velos mass spectrometer we identified 41 unique MS/MS spectra corresponding to 11 different peptides of PPP1R2/ PPP1R2P3. From these, 5 MS/MS spectra correspond to 2 peptides that match uniquely with PPP1R2, 3 MS/ MS spectra correspond to a peptide that matches uniquely to PPP1R2P3 and the remaining correspond to common sequences (Table 1 and Figure 1). The

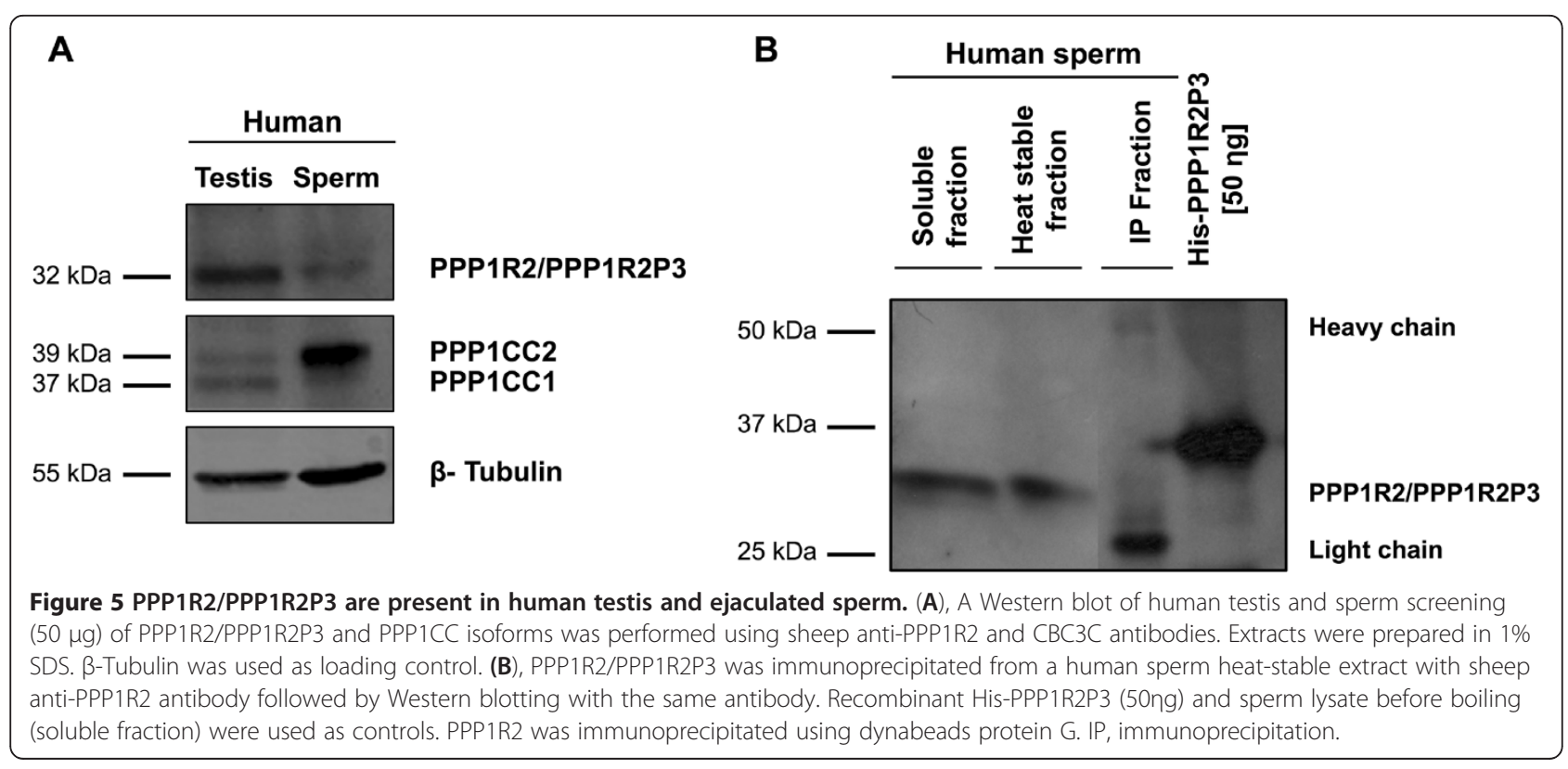


overall sequence coverage was $64 \%$ for PPP1R2 and $57 \%$ for PPP1R2P3. The mascot scores for each protein were near 600 (additionally, spectra were manually evaluated). This is the first report of PPP1R2 and PPP1R2P3 recovery from multiple extracts of human sperm, using two different antibodies.

Mass spectrometry data of the same immunoprecipitates showed that PPP1CC2 was also present. Five peptides out of $10 \mathrm{MS} / \mathrm{MS}$ spectra were identified, that matched PPP1CC2 with $15 \%$ coverage and a protein MASCOT score higher than 200 (manually evaluated). The results show that PPP1CC2 binds to PPP1R2/PPP1R2P3 in human spermatozoa (Table 1).
In extracts from ejaculated sperm, three independent peptides show post-translational modifications, identified as phosphorylation at Ser121, Ser122 and Ser127. However, they could not be assigned to either PPP1R2 or PPP1R2P3, given that both proteins are identical in that region. To our knowledge, this is the first time that phosphorylation of Ser127 has been reported for PPP1R2/PPP1R2P3. Tyrosine or threonine phosphorylations were not detected. The peptides obtained with phosphorylations correspond to only $7 \%$ of the total number of obtained peptides, strongly supporting the fact that PPP1R2/PPP1R2P3 are predominantly not phosphorylated.

Table 1 Peptides identified by Orbitrap Velos mass spectrometry for PPP1R2, PPP1R2P3 or both and for PPP1CC2, after immunoprecipitation of human sperm samples with sheep or rabbit anti-PPP1R2 antibodies. aa, amino acids; pl, isoelectric point

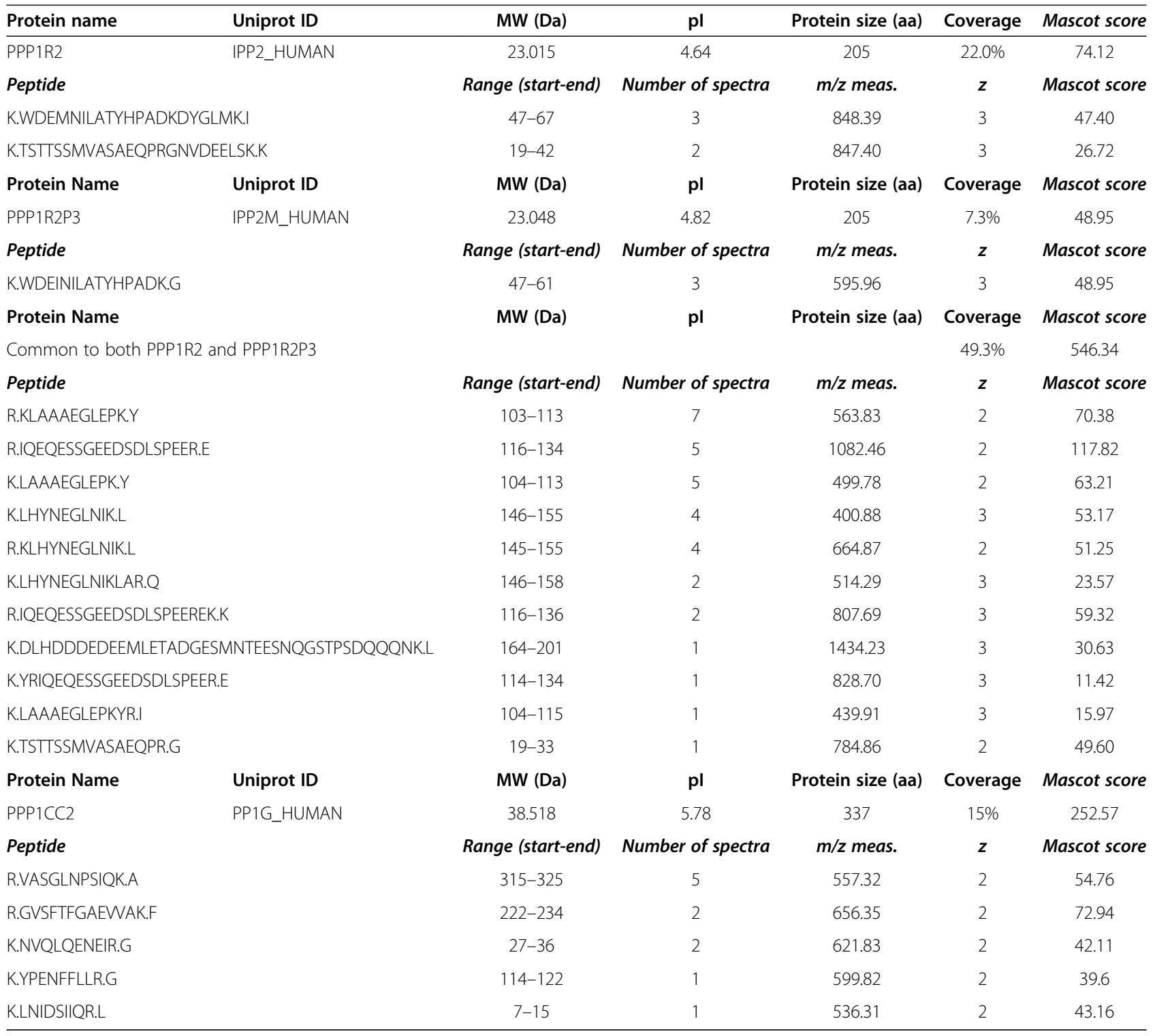


PPP1R2 subcellular-localization in human spermatozoa Immunocytochemistry was used to study the subcellular localization of PPP1R2 and PPP1R2P3 and their co-localization with PPP1CC2 in mature human spermatozoa. Experiments were performed using sheep antiPPP1R2 (detects PPP1R2 and PPP1R2P3) and CBC502 antibodies (Figure 6). Results showed that PPP1R2 and PPP1R2P3 are present along the flagellum, in the midpiece, principal piece, except the end-piece, and also in the head, more specifically in the equatorial and postacrosomal regions (Figure 6B). PPP1CC2 localization is similar, co-localizing to the same regions as seen with PPP1R2. A negative control using only secondary antibodies showed that the staining was specific (Figure 6A). The PPP1CC2 localization corroborated a previous report and the localization is consistent with a role for PPP1 in sperm forward and hyperactivated motility and possibly in the acrosome reaction [3-5,7,35]. To support the immunolocalization data, RIPA soluble extracts and insoluble fractions were resolved by SDS-PAGE and immunoblotted (Figure 7A). The results showed that PPP1R2 and PPP1R2P3 were mainly present in the soluble extracts. Although RIPA lysis buffer is a stringent buffer we still detected some PPP1R2 protein in the insoluble fraction. In contrast, PPP1CC2 is present in both fractions but more abundantly in the insoluble fraction. These results are consistent with PPP1CC2 being tightly attached to the axoneme.

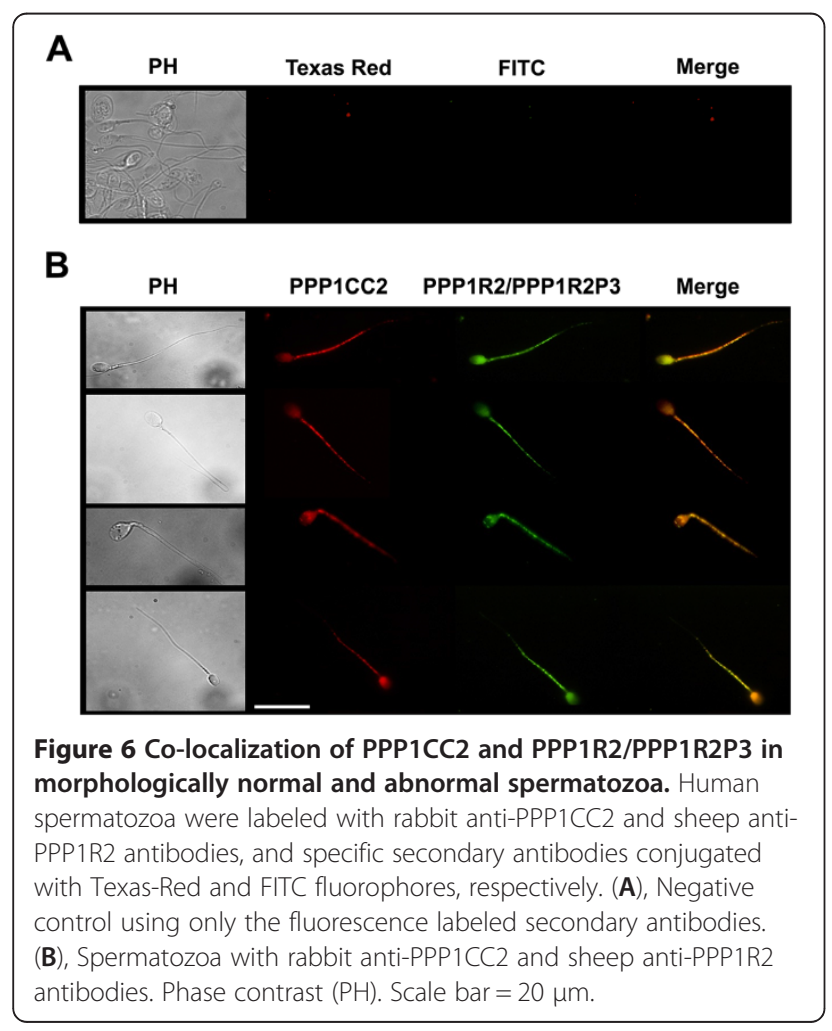

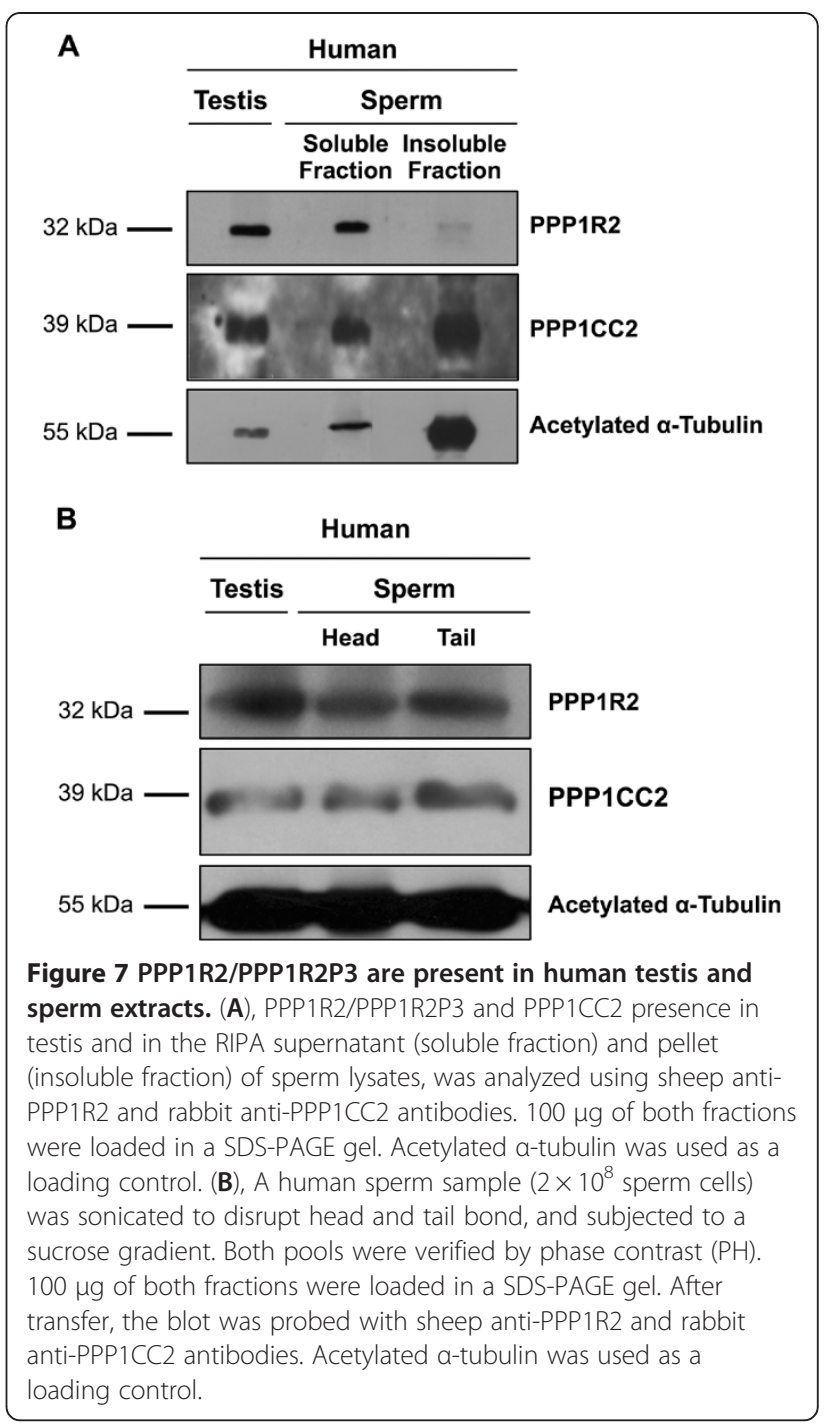

Furthermore, tail and head preparations were also obtained using a sucrose gradient. In this separation although heads are kept intact, tails are demembranated and only the axoneme structure is maintained, thus all soluble proteins present in the tail are removed. The results clearly demonstrate that PPP1R2 and PPP1R2P3, as well as PPP1CC2, are present in the spermatozoa tail and head and in similar amounts (Figure 7B).

\section{Phosphorylation of PPP1R2/PPP1R2P3 in human sperm}

Western blotting of human sperm heat-treated extracts revealed, depending on the samples, two bands migrating slower than the purified PPP1R2 and PPP1R2P3 (Figure 8A). To investigate the nature of those bands, human sperm heat-treated extracts were resolved by $2 \mathrm{D}$ PAGE, revealing three isolated spots of different molecular mass and $\mathrm{pI}$, suggesting the existence of different phosphorylated forms of PPP1R2 and PPP1R2P3 (Figure 8B, arrowheads). Besides threonine and serine, 
PPP1R2 can also be tyrosine phosphorylated [36,37]. The human sperm heat-treated extract was dephosphorylated by treatment with protein tyrosine phosphatase 1B (PTP), calf intestinal phosphatase (CIP) and PPP1CC1. Under the conditions used, only CIP, a nonspecific phosphatase, could dephosphorylate the PPP1R2 and PPP1R2P3, with an increase in electrophoretic mobility. This band however did not run at the same molecular mass as recombinant PPP1R2 (Figure 8C). When sperm PPP1R2 was incubated with GSK3 or CK2 or both, only GSK3 was able to induce a mobility shift (Figure 8D).

\section{Conclusions}

The data here presented clearly shows that PPP1R2 is present in human sperm, based on immunoreactivity and mass spectrometry analysis. This supports the model that the PPP1 inhibitor activity identified several years ago can be accounted for by PPP1R2 [3,5]. In the past, PPP1R2 mRNAs of $1.2 \mathrm{~kb}, 1.4-1.7 \mathrm{~kb}, 2.4-2.7 \mathrm{~kb}$ and $4 \mathrm{~kb}$ have been found in rat and rabbit testis [28]. These mRNAs strictly correspond to the polyadenylation (polyA) signals present in PPP1R2. Further, a new highly expressed testis-specific $0.9-1.1 \mathrm{~kb}$ message, presumably spliced from the PPP1R2 gene was also found in rabbit and rat. This message only was detected after 50 days and not before 20 days of age in rats [28,37]. Another report identified PPP1R2 protein in heat-stable extracts of bull testis and mouse testis and sperm [35]. Of particular relevance we identified, by mass spectrometry, a second PPP1R2-related protein in human sperm, termed PPP1R2P3. This was previously considered to be a pseudogene because it lacks introns, has no parental promoter, and seems to be integrated in the genome at a random new location. Pseudogenes originate from retrotransposition activity, so they have truncated 5'UTR due to the low processivity of the reverse transcriptase, and direct repeats at both ends [38]. Testis is an organ where many pseudogenes are expressed as mRNA and proteins that have been shown to actively participate in spermatogenesis or other germ cell functions [39,40]. Transcription in testis, when compared to other somatic tissues, tends to activate alternative promoters, which are otherwise imperfect or weak [40,41]. The apparent function of pseudogenes in testis germ cells could be a way to facilitate the appearance of new genes from the parental ones [39].

Previous work suggests that PPP1CC2 plays a key role in sperm motility. This enzyme is likely regulated by a

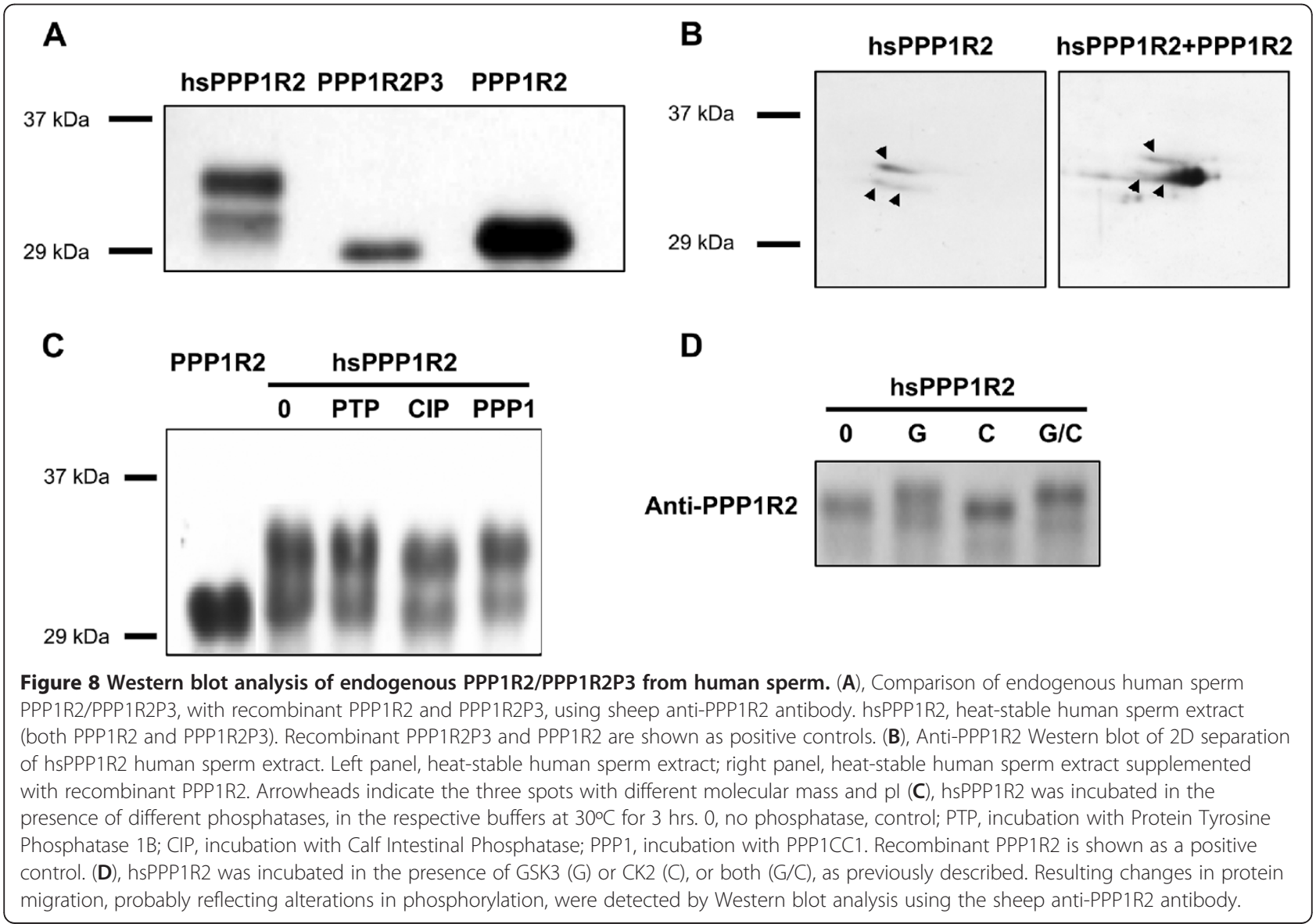


mechanism involving reversible phosphorylation of a PPP1R2 mediated by GSK3 kinase [3,5]. Peptides for PPP1CC2 were recovered in immunoprecipitates of PPP1R2/PPP1R2P3, indicating the presence of complexes between the enzyme and the inhibitors in sperm. Since immunoprecipitation was through antibodies against PPP1R2 the presence of other regulatory subunits were not determined. However, the results support the view that at least a proportion of PPP1 in sperm is likely to be regulated by PPP1R2 proteins. Our results also show that PPP1R2P3 is phosphorylated by CK2 in vitro, probably at residues 121,122 or 127 , as shown by the MS-MS spectra, even though the Ser87 is absent. Peptides previously assigned to PPP1R2P3 protein may have been derived also from PPP1R2 [42,43]. Acetylation at Ala2 and phosphorylation at Ser121 and Ser122 were observed by high throughput shotgun MS analysis in human Jurkat T cell leukemia and embryonic kidney (HEK293) cell lines $[42,43]$. These regions (Ala2, Ser121 and Ser122) are similar in both PPP1R2 and PPP1R2P3.

PPP1R2 interaction with PPP1C involves two primary motifs, ${ }^{145} \mathrm{KLHY}^{148}$ and ${ }^{43} \mathrm{KSQKW}^{47}$. Other points of contact in PPP1R2 are the N-terminal SILK motif $\left({ }^{12} \mathrm{KGILK}^{16}\right.$, in humans) that possibly initiates the binding, and the C-terminal acidic stretch, required for the PPP1 activation by GSK3 $[28,44,45]$. We show for the first time that PPP1R2P3 has all the PPP1 binding motifs, but lacks the key phosphorylation sites Thr73 and Ser87. These results are consistent with a model whereby PPP1R2P3 forms a complex with PPP1C but the activity of this complex would not be regulated by GSK3. The data show that PPP1R2P3 protein binds directly to PPP1CC and that this inhibitor cannot be phosphorylated by GSK3. The presence of this protein variant, which may be an irreversible inhibitor of PPP1CC provides for a novel mode of regulating the catalytic activity of the phosphatase (Figure 4).

Intrasperm localization analysis showed that both PPP1R2/PPP1R2P3 and PPP1CC2 co-localize in the same sperm subcellular structures. That is, PPP1CC2 is probably bound to the axoneme along with PPP1R2/ PPP1R2P3 (Figures 5, 6 and 7). A previous report showed that PPP1 in Chlamydomonas is anchored to the central pair apparatus of the axoneme, associated with the $\mathrm{C} 1$ microtubule and to a lesser extent to the outer doublet microtubules. This axonemal localization suggests that PPP1 can control both dynein arms and thereby kinetic activity of the flagellum [46]. Moreover, PPP1C has a two-fold higher activity in immotile bovine caput epididymal sperm compared to mature motile caudal sperm which is consistent with it being directly involved in sperm motility $[3,5]$. The regulation of sperm motility by this phosphatase should involve its inhibitors. We hypothesize that in the initial segments of the epididymis (caput) sperm are immotile due to the reversible activity of the PPP1R2/PPP1CC2 complexes, while in the latter segments of the epididymis (cauda), PPP1R2P3 substitutes for PPP1R2 as an irreversible inhibitor of PPP1CC2 thereby resulting in sperm motility. These independent interactions may be occurring concurrently, since peptides specific for both proteins were identified in ejaculated sperm. Since sperm are terminally differentiated cells, essentially devoid of transcriptional and translational activity, regulation occurs through pre-existing proteins and not through new synthesis of proteins. It is possible that PPP1R2P3 could be bound to another protein that may keep it from binding to PPP1CC2 in immotile caput sperm, in a similar manner to what is suggested to occur with sds22 (PPP1R7) in caput sperm [47]. Also, other PPP1CC2 complexes exist in sperm as dimers or trimers: such as PPP1R11/ PPP1R7/PPP1CC2 [6,22].

This mechanism of controlling sperm motility by PPP1CC2 and GSK3 may operate only in mammals, since other vertebrate classes do not have this alternatively spliced phosphatase [33]. Furthermore, PPP1R2P3 protein, which is only present in primates, could lead to a novel regulatory mechanism for regulating PPP1CC2 activity that might have evolved only in this order. Determination of the validity of these possibilities needs further studies. Work is in progress in our laboratory to determine the mechanistic role of PPP1R2 and PPP1R2P3 in regulating PPP1CC2 activity and thereby motility and fertility of spermatozoa.

\section{Methods}

\section{Yeast two-hybrid}

Methods for yeast two-hybrid screening of a human testis cDNA library using human PPP1CC have been previously described $[15,48,49]$. DNA sequence analysis was performed using an ABI PRISM 310 Genetic Analyser (Portugal Applied Biosystems, Porto, Portugal). The DNA sequences obtained were compared to the NCBI database, using the BLAST algorithm (http:// BLAST.ncbi.nlm.nih.gov/). The multiple sequence alignments were performed using the ClustalW program from Ensembl.

\section{PPP1R2 and PPP1R2P3 cloning, expression and purification}

The cDNA of PPP1R2P3 was ligated into the pET28c (Novagen, Madison, Wisconsin, USA) expression vector using EcoRI and XhoI restriction sites, adding a histidine tag (His-tag) to the N-terminus of the protein. The pETPPP1R2P3 sequence was verified and the plasmid transformed into E. coli strain Rosetta (DE3) (Novagen, Madison, Wisconsin, USA). The expression of His-tag PPP1R2P3 was induced with $1 \mathrm{mM}$ isopropyl $\beta$-D-1- 
thiogalactopyranoside (IPTG) for $3 \mathrm{hrs}$ at $37^{\circ} \mathrm{C}$ and the protein purified using a Ni-NTA resin (QIAGEN, Dusseldorf, Germany) according to the supplier's instructions. Briefly, the cells were lysed in $10 \mathrm{mM}$ imidazole, sodium phosphate buffer, $\mathrm{pH}$ 8.0, centrifuged at $15000 \mathrm{~g}$ for $30 \mathrm{~min}$ at $4^{\circ} \mathrm{C}$, and the supernatant was applied to the resin. The resin was washed with $20 \mathrm{mM}$ imidazole and the His-tag PPP1R2P3 was eluted with $500 \mathrm{mM}$ imidazole. The protein was further purified by $12 \%$ SDS-PAGE. A portion of the lane containing PPP1R2P3 was stained with Coomassie blue and the region containing the remaining protein was excised, washed three times with water, cut into smaller pieces and $1 \mathrm{ml}$ of $100 \mathrm{mM}$ Tris- $\mathrm{HCl}, \mathrm{pH} 8.5$, $0.1 \%$ SDS was added before freezing at $-20^{\circ} \mathrm{C}$ overnight. The slurry was frozen and thawed three times and then passed through a $0.22 \mu \mathrm{m}$ filter membrane. The gel-free filtrate was then dialyzed against $4 \times$ $500 \mathrm{ml}$ of $10 \mathrm{mM}$ Tris- $\mathrm{HCl}, \mathrm{pH} 7.5$ buffer for $24 \mathrm{hrs}$ at $4^{\circ} \mathrm{C}$. The protein concentration of recombinant His-PPP1R2P3 was determined by $\mathrm{BCA}^{\circledR}$ assay (Fisher Scientific, Loures, Portugal). PPP1R2P3 cDNA was also ligated into the pTACTAC expression vector [50] in the NdeI and $\mathrm{XbaI}$ restriction sites, the sequence verified and then transformed into Rosetta strain. The expression of PPP1R2P3 was induced with $0.4 \mathrm{mM}$ IPTG for $3 \mathrm{hrs}$ at $37^{\circ} \mathrm{C}$. The protein was partially purified by boiling the bacterial extract (here on referred to as recombinant PPP1R2P3) as previously described for PPP1R2 [25]. PPP1R2 CDNA was likewise ligated in PTACTAC expression vector [50] and recombinant protein purified in the same way as for PPP1R2P3 (here on referred to as recombinant PPP1R2). PPP1R2P3 cDNA was excised using EcoRI and XhoI from pET-PPP1R2P3 and subcloned in pACT-2 vector (Clontech, Saint Germain-en-Laye, France) for co-transformation.

\section{Yeast co-transformation with plasmid DNA}

Yeast competent AH109 cells were co-transformed with pACT-PPP1R2P3 and pAS2-PPP1CA, pAS2-PPP1CC1, pAS2-PPP1CC2 or pAS2-PPP1CC2end, by the lithium acetate method [15]. pAS2-PPP1CC constructs used were previously described [15]. For negative and positive controls pAS2-1/pACT-2 and pVA3-1/pTD1-1 vectors were used, respectively. Afterwards, the transformation mixture was plated on selective media containing X.alpha;-Gal and incubated at $30^{\circ} \mathrm{C}$ to check for MEL1 expression as indicated by the appearance of a blue color (Clontech, Saint Germain-en-Laye, France).

\section{Blot overlay analysis}

For blot overlay analysis, $0.3 \mu \mathrm{g}$ of commercial PPP1R2 (NEB, New England Biolabs, Herts, UK) and recombinant
His-PPP1R2P3 were resolved by SDS-PAGE and then transferred to a nitrocellulose membrane. Blots were overlaid with purified PPP1CC1 or PPP1CC2 $(25 \mathrm{pmol} / \mathrm{mL})$ diluted in Tris buffered saline with Tween-20/BSA [48,51] and detected with the antibodies $\mathrm{CBC} 3 \mathrm{C}$ (against the $\mathrm{C}$ terminal of PPP1CC, which detects both isoforms [52]) or CBC502 (specific for the C-terminal of PPP1CC2), both raised in rabbit. Immunoreactive bands were revealed by incubating with horseradish peroxidase conjugated antirabbit secondary antibody and developed by enhanced chemiluminescence (ECL, GE Healthcare, Amersham Biosciences Europe GmbH, Freiburg, Germany).

\section{Phosphatase activity assays}

The IC50 values of PPP1R2 and PPP1R2P3 for purified PPP1CC1 and PPP1CC2 isoforms were determined using [32P]phosphorylase a as substrate. The substrate was prepared from phosphorylase b (Sigma-Aldrich

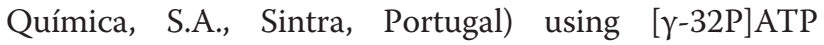
(3000 Ci/mmol, GE Healthcare, Amersham Biosciences Europe GmbH, Freiburg, Germany) and phosphorylase kinase (Sigma-Aldrich Química, S.A., Sintra, Portugal) as previously described [48]. An appropriate range of concentrations of commercial PPP1R2 and His-PPP1R2P3 were incubated with the purified PPP1C isoforms and the phosphatase activity determined. The IC50 was calculated using the BioDataFit 1.02 software (Chang Bioscience, Castro Valley, California, USA).

\section{Sperm extracts}

Ejaculated sperm were collected from healthy donors by masturbation into an appropriate sterile container. Spermograms were performed by experienced technicians and only samples with normal parameters were used [53]. For all the methods, sperm was washed three times in $1 \times$ PBS. For immunoprecipitation, sperm was lysed in 1× RIPA buffer (radioimmunoprecipitation buffer, Millipore Iberica S.A.U., Madrid, Spain) supplemented with protease $(10 \mathrm{mM}$ benzamidine, $1.5 \mu \mathrm{M}$ aprotinin, $5 \mu \mathrm{M}$ pepstatin A, $2 \mu \mathrm{M}$ leupeptin, $1 \mathrm{mM}$ PMSF) and phosphatase ( $1 \mathrm{mM}$ sodium fluoride, $2.5 \mathrm{mM}$ sodium pyrophosphate, $50 \mathrm{mM}$ beta-glycerophosphate, $1 \mathrm{mM}$ sodium orthovanadate) inhibitors, sonicated $3 \times$ for $10 \mathrm{sec}$ and centrifuged at $16000 \mathrm{~g}$ for $20 \mathrm{~min}$, at $4^{\circ} \mathrm{C}$. The supernatant was collected and heat-stable extracts were prepared by immersing the sample in a boiling water bath for $30 \mathrm{~min}$, chilled on ice for $2 \mathrm{~min}$ and centrifuged at $16000 \mathrm{~g}$ for $20 \mathrm{~min}$, at $4^{\circ} \mathrm{C}$. The final supernatant was used in the subsequent steps. For Western blot, both the supernatant (soluble fraction) and the pellet (insoluble fraction) were resuspended in $1 \%$ SDS [54].

For the preparation of heads and tails, washed sperm were briefly sonicated and the detachment checked by phase contrast microscopy (PH) using an Olympus IX81 
epifluorescence microscope, equipped with appropriate software (Olympus Portugal - Opto-Digital Tecnologias, S.A., Lisboa, Portugal). Sperm were directly applied onto a sucrose step gradient $(1.8 \mathrm{M}, 2.02 \mathrm{M}$ and $2.2 \mathrm{M})$ to separate heads from tails, by centrifuging at $5000 \mathrm{~g}$ for $1 \mathrm{hr}$ and fractions corresponding to tails and heads collected. Subsequently fractions were centrifuged at $16000 \mathrm{~g}, 10 \mathrm{~min}$, resulting in a pellet free of sucrose and proteins were dissolved in 1\% SDS. For immunocytochemistry, washed sperm was used directly on the coverslips. Human testicular biopsy was also prepared using $1 \%$ SDS and the same protocol as for sperm samples, but previously homogenized using a tissue homogenizer. Testicular biopsy was collected in Centro Hospitalar de Coimbra, Portugal during a procedure to collect organs for transplantation from a brain death 35-years-old adult man and the biopsy was diagnosed as "normal spermatogenesis" based on histopathological analysis.

\section{Consent}

Written informed consent, for the use of sperm samples, was obtained from the donors for publication and any accompanying images. A copy of the written consent is available for review by the Editor-in-Chief of this journal. The study was conducted in accordance with the guidelines of the "Helsinki Declaration".

Testicular biopsies for research purposes are covered by the legislation of the Portuguese Constitution (decretolei no274/99 of July 22, 1999: "It is permitted the dissection of corpses, or parts of them, of national citizens, stateless persons and foreign residents in Portugal, as well as extraction of parts, tissues or organs when the deceased has explicitly declared in life's will that his body can be used for purposes of teaching and scientific research.").

\section{Phosphorylation of PPP1R2 and PPP1R2P3}

Recombinant PPP1R2, PPP1R2P3 or human sperm heat extract of native PPP1R2/PPP1R2P3 (about 200 ๆg of

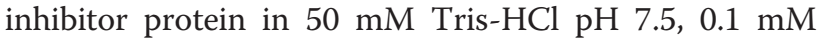
EGTA and $0.03 \%$ Brij-35) were phosphorylated by GSK3 $\beta$ or CK2 (Calbiochem, MERCK, Darmstadt, Germany) or both kinases as previously described [28]. The phosphorylation reaction was run at $30^{\circ} \mathrm{C}$ for $90 \mathrm{~min}$ and then terminated with the addition of $4 \times$ SDS loading buffer. Two separate $12 \%$ gels were run, one with $1 / 10$ of the reaction volume and the other with the remaining $9 / 10$ of the reaction volume. The $1 / 10$ reaction gel was transferred and analyzed by Western blot while the $9 / 10$ reaction gel was dried and autoradiographed.

\section{Immunoprecipitation}

RIPA supernatant sperm extracts were pre-cleared using dynabeads protein G (Life Technologies S.A., Madrid,
Spain). A direct immunoprecipitation approach was performed with $1 \mu \mathrm{g}$ of sheep anti-PPP1R2 or rabbit anti-PPP1R2 pre-incubated with Dynabeads ${ }^{\circledR}$ Protein G during $1 \mathrm{hr}$ at $4^{\circ} \mathrm{C}$ with rotation. After incubation, pre-cleared sperm extracts were applied to the antibodydynabeads complex and incubated overnight with rotation at $4^{\circ} \mathrm{C}$. After washing three times with $1 \times \mathrm{PBS}$ in $3 \% \mathrm{BSA}$ for $10 \mathrm{~min}$ with rotation at $4^{\circ} \mathrm{C}$, beads were resuspended in loading buffer and boiled.

\section{Mass spectrometry}

For mass spectrometry analysis, immunoprecipitates were resolved by $10 \%$ SDS-PAGE along with purified positive controls. Gels were stained with Coomassie blue colloidal (Sigma-Aldrich Química, S.A., Sintra, Portugal). In brief, gels were fixed with a fixation solution $(40 \%$ methanol and $10 \%$ acetic acid) during $1 \mathrm{hr}$, washed with distilled water and then transferred to the Coomassie blue colloidal staining solution for $1 \mathrm{hr}$. After staining, the gels were washed with distilled water and afterwards destained with $25 \%$ methanol until bands were visualized.

Bands were excised directly from the gel using a spatula and completely destained. In-gel digestion was performed overnight at $37^{\circ} \mathrm{C}$ with trypsin (Promega, Madison, Wisconsin, USA) in $10 \mathrm{mM} \mathrm{HCl}$ and $50 \mathrm{mM}$ ammonium hydrogen carbonate $\left(\mathrm{NH}_{4} \mathrm{HCO}_{3}\right)$ at $\mathrm{pH} 7.8$. Resulting peptides were extracted once with $100 \mu \mathrm{l}$ of $1 \%$ formic acid (FA), and twice with $100 \mu \mathrm{l}$ of 5\% FA, $50 \%$ acetonitrile $(\mathrm{ACN})$. Extracts were combined and ACN was removed in vacuo. For LC-MS analysis, a final volume of $40 \mu \mathrm{l}$ was prepared by addition of 1\% FA. Electrospray tandem mass spectrometry (ESI-MS/MS) was performed on an Orbitrap Velos instrument (Thermo Scientific, Bremen, Germany). Fragment ions were generated by low-energy collision-induced dissociation (CID) on isolated ions with a fragmentation amplitude of $0.5 \mathrm{~V}$. MS spectra were summed from four individual scans ranging from $\mathrm{m} / \mathrm{z}$ 300-1500 with a scanning speed of $8.100(\mathrm{~m} / \mathrm{z}) / \mathrm{s}$. MS/MS spectra were a sum of two scans ranging from $\mathrm{m} / \mathrm{z}$ $100-2800$ at a scan rate of $26.000(\mathrm{~m} / \mathrm{z}) / \mathrm{s}$. Generated data were imported to ProteinScape ${ }^{\mathrm{TM}}$, a proteomics data platform (Bruker Daltonik GmbH, Bremen, Germany) and analyzed using MASCOT (version 2.2.0, Matrix Science, London, UK) search algorithm with search parameters as follows: precursor ion tolerance of 1.2 and $0.3 \mathrm{Da}$ for MS/ MS spectra. Proteins were considered to be identified if the Mascot score (ProteinScape ${ }^{\mathrm{TM}}$ ) was higher than 65 .

\section{Western blotting}

Extracts were mass normalized using $\mathrm{BCA}^{\circledR}$ assay (Fisher Scientific, Loures, Portugal). Immunoprecipitates and extracts were resolved by $10 \%$ SDS-PAGE. Proteins were subsequently electrotransferred onto nitrocellulose membranes 
and immunodetected with the appropriate antibodies, using ECL detection (GE Healthcare Spain, Madrid, Spain). The primary antibodies used in this study included sheep polyclonal anti-PPP1R2 (1:100), the rabbit CBC502 (1:2000, against the $\mathrm{C}$-terminal of $\mathrm{PPP} 1 \mathrm{CC} 2$ ), the rabbit $\mathrm{CBC} 3 \mathrm{C}$ (1:1000, against the C-terminal and detects both PPP1CC isoforms) and the loading controls, mouse monoclonal anti$\beta$-tubulin (1:500, Life Technologies S.A., Madrid, Spain) and mouse monoclonal acetylated- $\alpha$-tubulin (1:2000, Life Technologies S.A., Madrid, Spain). The secondary antibodies used were horseradish peroxidase-conjugated anti-rabbit (1:5000), anti-sheep (1:1000) and anti-mouse (1:5000) IgGs for ECL detection (GE Healthcare, Amersham Biosciences Europe GmbH, Freiburg, Germany).

\section{Immunocytochemistry}

An aliquot of washed diluted sperm $(25 \mu \mathrm{l})$ was placed onto a glass coverslip pre-coated with $100 \mu \mathrm{g} / \mathrm{ml}$ poly-L-ornithine, and dried at room temperature, in a six-well plate containing one coverslip per well. To each well $1 \mathrm{ml}$ of $4 \%$ paraformaldehyde in 1× PBS was gently added and left to stand for $10 \mathrm{~min}$. Subsequently, sperm sample was washed twice with $1 \mathrm{ml} 1 \times$ PBS for $10 \mathrm{~min}$. For permeabilization, $1 \mathrm{ml}$ of 1:1 methanol/acetone solution was added for $2 \mathrm{~min}$ and then the samples washed twice with $1 \mathrm{ml} 1 \times$ PBS for 10 min and blocked for $1 \mathrm{hr}$ with 3\% BSA in $1 \times$ PBS, before incubation with primary antibodies (rabbit CBC502, 1:250 and sheep anti-PPP1R2, 1:100) for 2 hrs at room temperature. After three washes with $1 \times$ PBS, the fluorescently labeled secondary antibodies anti-rabbit Texas-Red, 1:300 (MolecularProbes, Eugene, USA) and anti-sheep FITC, 1:50 (DAKO, Glostrup, Denmark) were added and the coverslips incubated for 2 hrs. Finally, three washes with $1 \times$ PBS were performed and coverslips were mounted on microscope glass slides with one drop of anti-fading reagent containing DAPI for nucleic acid staining (Vectashield, Vector Laboratories Burlingame, California, USA). Images were acquired using an Olympus IX81 epifluorescence microscope and digital camera, equipped with the appropriate software (Olympus Portugal-Opto-Digital Tecnologias, S.A., Lisboa, Portugal).

\section{D-PAGE analysis}

The human sperm heat-stable extracts (hsPPP1R2) or hsPPP1R2 plus $10 \eta \mathrm{g}$ of recombinant PPP1R2 were acetone precipitated and the pellets were resuspended in $250 \mathrm{\mu l}$ of $2 \mathrm{D}$ rehydration solution (8 M Urea/ 2 M Thiourea/ 2\% CHAPS/ $0.002 \%$ of bromophenol blue) and supplemented with $2.5 \mu \mathrm{l}$ of IPG buffer (in the 4-7 pH range) and $14 \mathrm{mg}$ of DTT. The samples were pipetted into a strip holder and the electrophoresis was started $(1 \mathrm{hr}$ at $30 \mathrm{~V}, 2 \mathrm{hrs}$ at $150 \mathrm{~V}, 1 \mathrm{hr}$ at $500 \mathrm{~V}, 1 \mathrm{hr}$ at $1000 \mathrm{~V}$ and $2 \mathrm{hrs}$ at $8000 \mathrm{~V})$. After the second dimension on $12 \%$ gels, samples were analyzed by Western blot.

\section{Dephosphorylation of human sperm PPP1R2/PPP1R2P3}

The hsPPP1R2 extracts were incubated overnight with either protein tyrosine phosphatase 1B (Upstate, Millipore Iberica S.A.U., Madrid, Spain) at $37^{\circ} \mathrm{C}$, calf intestinal phosphatase (NEB, New England Biolabs (UK), Herts, UK) at $37^{\circ} \mathrm{C}$ or $\mathrm{PPP} 1 \mathrm{CC} 1$, at $30^{\circ} \mathrm{C}$, with the respective assay buffers. The reactions were stopped with the addition of $4 \times$ SDS loading buffer and analyzed by Western blot.

\begin{abstract}
Abbreviations
GSK3: Glycogen synthase kinase 3; CK2: Casein kinase 2; PPP1: Phosphoprotein phosphatase 1; PPP1C: Catalytic subunit of PPP1; PPP1R2: PPP1 regulator 2; PPP1R2P3: PPP1R2 pseudogene 3; IPTG: Isopropyl $\beta$-D-1-thiogalactopyranoside; ECL: Enhanced chemiluminescence; RIPA: Radioimmunoprecipitation buffer; PH: Phase contrast microscopy; FA: Formic acid; ACN: Acetonitrile; ESI-MS/MS: Electrospray mass spectrometry; CID: Low-energy collision-induced dissociation; FITC: Fluorescein isothiocyanate; DAPI: 4',6-diamidino-2-phenylindole; DTT: Dithiothreitol; IPG: Immobilized pH gradient; EST: Expressed sequence tag; MGC: Mammalian gene collection; HEK293: Human embryonic kidney 293 cells; pl: Isoelectric point; aa: Amino acid; IP: Immunoprecipitation.
\end{abstract}

\section{Competing interests}

The authors declare that they have no competing interests.

\section{Authors' contributions}

Performed the sequence alignment: LKG. Conceived and designed the experiments: $L K G, M F e, A P V, W W, M F$ and EFCS. Performed the experiments: LKG, MFe, APV, WW and TM. Analyzed the data: LKG, MFe, APV, WW and TM. Contributed with reagents/materials/analysis tools: KM, SV, DLB, OABCS, MF and EFCS. Wrote the first draft: LKG. Edited the first draft: MFe, SV, DLB, OABCS and MF. All authors read and approved the final manuscript.

\section{Acknowledgements}

This work was supported by the Centre for Cell Biology of the University of Aveiro, by grants from FCT of the Portuguese Ministry of Science and Higher Education to LKMG (SFRH/BD/42334/2007), WW (SFRH/BD/6879/2001) and EFCS (POCI/SAU-OBS/57394/2004, PPCDT/SAU-OBS/57394/2004, REEQ/1023/ $\mathrm{BIO} / 2005)$, CRUP (E-92/08;B-32/09) and USPHS grant GM56362 from the National Institutes of Health, USA (to DLB).

Margarida Fardilha dedicates this paper to the memory of her mentor EFCS (Edgar Figueiredo da Cruz e Silva, deceased) who believed that PPP1R2 and PPP1R2P3 proteins were the key to explain sperm motility initiation, but unfortunately could not conclude the proof of his theory during his lifetime. Collaborators (David L. Brautigan and S. Vijayaraghavan) worked with EFCS on PPP1 and PPP1R2 for many years.

\section{Author details}

'Laboratory of Signal Transduction, Centre for Cell Biology, Biology Department, University of Aveiro, 3810-193 Aveiro, Portugal. ${ }^{2}$ Functional Proteomics Department, Medizinisches Proteom-Center, Ruhr-University Bochum, Universitaetsstr. 150, 44809, Bochum, Germany. ${ }^{3}$ Biological Sciences Biology Department, Kent State University, Kent, OH 44242, USA. ${ }^{4}$ Center for Cell Signaling, University of Virginia, School of Medicine, Charlottesville, VA 22908, USA. 5 Laboratory of Neurosciences, Centre for Cell Biology, Biology Department; Health Sciences Department, University of Aveiro, 3810-193 Aveiro, Portugal. ${ }^{6}$ Laboratory of Signal Transduction, Centre for Cell Biology, Biology Department; Health Sciences Department, University of Aveiro, 3810-193 Aveiro, Portugal. ${ }^{7}$ Centro de Biologia Celular, Universidade de Aveiro, 3810-193 Aveiro, Portugal.

Received: 5 July 2012 Accepted: 11 March 2013

Published: 18 March 2013 


\section{References}

1. Urner F, Sakkas D: Protein phosphorylation in mammalian spermatozoa. Reproduction 2003, 125(1):17-26.

2. Fardilha M, Esteves SLC, Korrodi-Gregório L, Pelech S, da Cruz e Silva OAB, da Cruz e Silva EF: Protein phosphatase 1 complexes modulate sperm motility and present novel targets for male infertility. Mol Hum Reprod 2011, 17(8):466-477.

3. Vijayaraghavan S, Stephens DT, Trautman K, Smith GD, Khatra B, da Cruz e Silva EF, Greengard P: Sperm motility development in the epididymis is associated with decreased glycogen synthase kinase-3 and protein phosphatase 1 activity. Biol Reprod 1996, 54(3):709-718.

4. Smith GD, Wolf DP, Trautman KC, Vijayaraghavan S: Motility potential of macaque epididymal sperm: the role of protein phosphatase and glycogen synthase kinase-3 activities. J Androl 1999, 20(1):47-53.

5. Smith GD, Wolf DP, Trautman KC, da Cruz e Silva EF, Greengard P, Vijayaraghavan S: Primate sperm contain protein phosphatase 1 , a biochemical mediator of motility. Biol Reprod 1996, 54(3):719-727.

6. Huang Z, Khatra B, Bollen M, Carr DW, Vijayaraghavan S: Sperm PP1gamma2 is regulated by a homologue of the yeast protein phosphatase binding protein sds22. Biol Reprod 2002, 67(6):1936-1942.

7. Ashizawa K, Wishart GJ, Katayama S, Takano D, Ranasinghe AR, Narumi K, Tsuzuki $Y$ : Regulation of acrosome reaction of fowl spermatozoa: evidence for the involvement of protein kinase $\mathrm{C}$ and protein phosphatase-type 1 and/or type 2A. Reproduction 2006, 131(6):1017-1024.

8. Varmuza S, Jurisicova A, Okano K, Hudson J, Boekelheide K, Shipp EB: Spermiogenesis is impaired in mice bearing a targeted mutation in the protein phosphatase 1cgamma gene. Dev Biol 1999, 205(1):98-110.

9. Chakrabarti R, Kline D, Lu J, Orth J, Pilder S, Vijayaraghavan S: Analysis of Ppp1cc-Null Mice Suggests a Role for PP1gamma2 in Sperm Morphogenesis. Biol Reprod 2007, 76(6):992-1001.

10. Ashizawa K, Wishart GJ, Tomonaga H, Nishinakama K, Tsuzuki Y: Presence of protein phosphatase type 1 and its involvement in temperaturedependent flagellar movement of fowl spermatozoa. FEBS Lett 1994, 350(1):130-134

11. Klumpp S, Cohen P, Schultz JE: Okadaic acid, an inhibitor of protein phosphatase 1 in Paramecium, causes sustained $\mathrm{Ca} 2(+)$-dependent backward swimming in response to depolarizing stimuli. EMBO J 1990, 9(3):685-689.

12. Habermacher G, Sale WS: Regulation of flagellar dynein by phosphorylation of a 138-kD inner arm dynein intermediate chain. J Cell Biol 1997, 136(1):167-176.

13. Bollen M, Peti W, Ragusa MJ, Beullens M: The extended PP1 toolkit: designed to create specificity. Trends Biochem Sci 2010, 35(8):450-458.

14. Fardilha M, Esteves SL, Korrodi-Gregorio L, da Cruz e Silva OA, da Cruz e Silva EF: The physiological relevance of protein phosphatase 1 and its interacting proteins to health and disease. Curr Med Chem 2010, 17(33):3996-4017.

15. Fardilha M, Esteves SLC, Korrodi-Gregório L, Vintém AP, Domingues SC, Rebelo S, Morrice N, Cohen PTW, da Cruz e Silva OAB, da Cruz e Silva EF: Identification of the human testis protein phosphatase 1 interactome. Biochem Pharmacol 2011, 82(10):1403-1415.

16. Nimmo GA, Cohen P: The regulation of glycogen metabolism. Purification and characterisation of protein phosphatase inhibitor-1 from rabbit skeletal muscle. European journal of biochemistry / FEBS 1978, 87(2):341-351.

17. Brautigan DL: Protein Ser/ Thr phosphatases - the ugly ducklings of cell signalling. FEBS J 2012, 280(2):324-345.

18. Hemmings BA, Resink TJ, Cohen P: Reconstitution of a Mg-ATP-dependent protein phosphatase and its activation through a phosphorylation mechanism. FEBS Lett 1982, 150(2):319-324.

19. Somanath PR, Jack SL, Vijayaraghavan S: Changes in sperm glycogen synthase kinase-3 serine phosphorylation and activity accompany motility initiation and stimulation. J Androl 2004, 25(4):605-617.

20. Vijayaraghavan S, Mohan J, Gray H, Khatra B, Carr DW: A Role for Phosphorylation of Glycogen Synthase Kinase3a in Bovine Sperm Motility Regulation. Biol Reprod 2000, 62(6):1647-1654.

21. Pilder SH, Lu J, Han Y, Hui L, Samant SA, Olugbemiga OO, Meyers KW, Cheng L, Vijayaraghavan S: The molecular basis of "curlicue": a sperm motility abnormality linked to the sterility of $t$ haplotype homozygous male mice. Soc Reprod Fertil Suppl 2007, 63:123-133.
22. Cheng L, Pilder S, Nairn AC, Ramdas S, Vijayaraghavan S: PP1gamma2 and PPP1R11 are parts of a multimeric complex in developing testicular germ cells in which their steady state levels are reciprocally related. PLoS One 2009, 4(3):e4861.

23. Sanseau P, Jackson A, Alderton RP, Beck S, Senger G, Sheer D, Kelly A, Trowsdale J: Cloning and characterization of human phosphatase inhibitor-2 (IPP-2) sequences. Mamm Genome 1994, 5(8):490-496.

24. Gerhard DS, Wagner L, Feingold EA, Shenmen CM, Grouse LH, Schuler $G$, Klein SL, Old S, Rasooly R, Good P, et al: The status, quality, and expansion of the NIH full-length CDNA project: the Mammalian Gene Collection (MGC). Genome Res 2004, 14(10B):2121-2127.

25. Helps NR, Street AJ, Elledge SJ, Cohen PTW: Cloning of the complete coding region for human protein phosphatase inhibitor 2 using the two hybrid system and expression of inhibitor 2 in E. coli. FEBS Lett 1994, 340(1-2):93-98.

26. Kim Y-M, Watanabe T, Allen PB, Kim Y-M, Lee S-J, Greengard P, Nairn AC, Kwon Y-G: PNUTS, a Protein Phosphatase 1 (PP1) Nuclear Targeting Subunit. J Biol Chem 2003, 278(16):13819-13828.

27. DePaoli-Roach AA: Synergistic phosphorylation and activation of ATP-Mg -dependent phosphoprotein phosphatase by F A/GSK-3 and casein kinase II (PC0.7). J Biol Chem 1984, 259(19):12144-12152.

28. Park IK, Roach P, Bondor J, Fox SP, DePaoli-Roach AA: Molecular mechanism of the synergistic phosphorylation of phosphatase inhibitor2. Cloning, expression, and site-directed mutagenesis of inhibitor-2. J Biol Chem 1994, 269(2):944-954.

29. Li M, Satinover DL, Brautigan DL: Phosphorylation and functions of inhibitor-2 family of proteins. Biochemistry 2007, 46(9):2380-2389.

30. Gruppuso PA, Johnson GL, Constantinides M, Brautigan DL: Phosphorylase phosphatase regulatory subunit. "Western" blotting with immunoglobulins against inhibitor-2 reveals a protein of $\mathrm{Mr}=60,000$. J Biol Chem 1985, 260(7):4288-4294.

31. Roach P, Roach PJ, DePaoli-Roach AA: Phosphoprotein phosphatase inhibitor-2. Identification as a species of molecular weight 31,000 in rabbit muscle, liver, and other tissues. J Biol Chem 1985, 260(10):6314-6317.

32. Reddy P, Ernst VG: Partial purification and characterization of heat stable protein phosphatase inhibitor-2 from rabbit reticulocytes. Biochem Biophys Res Commun 1983, 114(3):1089-1096.

33. Chakrabarti R, Cheng L, Puri P, Soler D, Vijayaraghavan S: Protein phosphatase PP1[gamma]2 in sperm morphogenesis and epididymal initiation of sperm motility. Asian J Androl 2007, 9(4):445-452.

34. Wang W, Stukenberg PT, Brautigan DL: Phosphatase Inhibitor-2 Balances Protein Phosphatase 1 and Aurora B Kinase for Chromosome Segregation and Cytokinesis in Human Retinal Epithelial Cells. Mol Biol Cell 2008, 19(11):4852-4862.

35. Si Y, Okuno M: Role of Tyrosine Phosphorylation of Flagellar Proteins in Hamster Sperm Hyperactivation. Biol Reprod 1999, 61 (1):240-246.

36. Williams JP, Jo H, Hunnicutt RE, Brautigan DL, McDonald JM: Tyrosine phosphorylation of phosphatase inhibitor 2. J Cell Biochem 1995, 57(3):415-422.

37. Osawa $Y$, Nakagama $H$, Shima $H$, Sugimura T, Nagao M: Identification and Characterization of three Isotypes of Protein Phosphatase Inhibitor-2 and their Expression Profiles during Testis Maturation in Rats. Eur J Biochem 1996, 242(3):793-798.

38. Rouchka E, Cha I: Current Trends in Pseudogene Detection and Characterization. Curr Bioinforma 2009, 4(2):112-119.

39. Kleene KC, Mulligan E, Steiger D, Donohue K, Mastrangelo MA: The mouse gene encoding the testis-specific isoform of Poly(A) binding protein (Pabp2) is an expressed retroposon: intimations that gene expression in spermatogenic cells facilitates the creation of new genes. $J$ Mol Evol 1998, 47(3):275-281.

40. Huang C-J, Lin W-Y, Chang C-M, Choo K-B: Transcription of the rat testisspecific Rtdpoz-T1 and -T2 retrogenes during embryo development: co-transcription and frequent exonisation of transposable element sequences. BMC Mol Biol 2009, 10(1):74.

41. Vinckenbosch N, Dupanloup I, Kaessmann H: Evolutionary fate of retroposed gene copies in the human genome. Proc Natl Acad Sci U S A 2006, 103(9):3220-3225.

42. Mayya V, Han DK: Phosphoproteomics by mass spectrometry: insights, implications, applications and limitations. Expert Rev Proteomics 2009, 6(6):605-618. 
43. Gauci S, Helbig AO, Slijper M, Krijgsveld J, Heck AJR, Mohammed S: Lys-N and Trypsin Cover Complementary Parts of the Phosphoproteome in a Refined SCX-Based Approach. Anal Chem 2009, 81(11):4493-4501.

44. Yang J, Hurley TD, DePaoli-Roach AA: Interaction of Inhibitor-2 with the Catalytic Subunit of Type 1 Protein Phosphatase. J Biol Chem 2000, 275(30):22635-22644.

45. Hurley TD, Yang J, Zhang L, Goodwin KD, Zou Q, Cortese M, Dunker AK, DePaoli-Roach AA: Structural basis for regulation of protein phosphatase 1 by inhibitor-2. J Biol Chem 2007, 282(39):28874-28883.

46. Yang P, Fox L, Colbran R, Sale W: Protein phosphatases PP1 and PP2A are located in distinct positions in the Chlamydomonas flagellar axoneme. J Cell Sci 2000, 113(1):91-102.

47. Mishra S, Somanath PR, Huang Z, Vijayaraghavan S: Binding and inactivation of the germ cell-specific protein phosphatase PP1gamma2 by sds22 during epididymal sperm maturation. Biol Reprod 2003, 69(5):1572-1579.

48. Browne GJ, Fardilha M, Oxenham SK, Wu W, Helps NR, da Cruz e Silva OA, Cohen PT, da Cruz e Silva EF: SARP, a new alternatively spliced protein phosphatase 1 and DNA interacting protein. Biochem J 2007, 402(1):187-196.

49. Fardilha M, Wu W, Sa R, Fidalgo S, Sousa C, Mota C, da Cruz e Silva OA, da Cruz e Silva EF: Alternatively spliced protein variants as potential therapeutic targets for male infertility and contraception. Ann N Y Acad Sci 2004, 1030:468-478.

50. Zhang ZJ, Bai G, Shima M, Zhao SM, Nagao M, Lee EYC: Expression and Characterization of Rat Protein Phosphatases1.alpha; -1 1 1, -1 Y2, and -18. Arch Biochem Biophys 1993, 303(2):402-406.

51. Watanabe T, da Cruz e Silva EF, Huang HB, Starkova N, Kwon YG, Horiuchi A, Greengard P, Nairn AC: Preparation and characterization of recombinant protein phosphatase 1. Methods Enzymol 2003, 366:321-338.

52. da Cruz e Silva EF, Fox CA, Ouimet CC, Gustafson E, Watson SJ, Greengard P. Differential expression of protein phosphatase 1 isoforms in mammalian brain. The Journal of neuroscience: the official journal of the Society for Neuroscience 1995, 15(5 Pt 1):3375-3389.

53. World Health Organization: WHO Laboratory for examination of human semen and sperm-cervical mucus interaction. In Collection and examination of human semen. Cambridge: Cambridge University Press; 1999:4-30.

54. Naz RK: Involvement of protein serine and threonine phosphorylation in human sperm capacitation. Biol Reprod 1999, 60(6):1402-1409.

doi:10.1186/1471-2121-14-15

Cite this article as: Korrodi-Gregório et al:: Identification and characterization of two distinct PPP1R2 isoforms in human spermatozoa. BMC Cell Biology 2013 14:15.

\section{Submit your next manuscript to BioMed Central and take full advantage of:}

- Convenient online submission

- Thorough peer review

- No space constraints or color figure charges

- Immediate publication on acceptance

- Inclusion in PubMed, CAS, Scopus and Google Scholar

- Research which is freely available for redistribution 